Open Access

Res. Agric., Livest. Fish.

Research Article

Vol. 1, No. 1, December 2014: 61-70

\title{
GLUTAMATERGIC CIRCUITS IN THE SONG SYSTEM OF ZEBRA FINCH BRAIN DETERMINED BY GENE EXPRESSION OF VGLUT2 AND GLUTAMATE RECEPTORS
}

\section{Mohammad Rabiul Karim ${ }^{1,2 *}$, Munmun Pervin ${ }^{3}$ and Yasuro Atoji ${ }^{2}$}

${ }^{1}$ Department of Anatomy and Histology, Faculty of Veterinary Science, Bangladesh Agricultural University, Mymensingh-2202, Bangladesh, 2Laboratory of Veterinary Anatomy, Gifu University, Japan and ${ }^{3}$ Laboratory of Veterinary Pathology, Osaka Prefecture University, Osaka, Japan

*Corresponding author: Mohammad Rabiul Karim, E-mail: rabivet@gmail.com

\section{ARTICLE INFO}

Received

29.09.2014

Accepted

17.11.2014

Online

27.12.2014

Key words:

Glutamateric neuron

Brain

In situ hybridization Songbird
The songbird brain has a system of interconnected nuclei that are specialized for singing and song learning. Electrophysiological findings indicate a role for the glutamatergic neurons in the song system. Vesicular glutamate transporter 2 (vGluT2) is considered to be a specific biomarker of glutamatergic neurons in birds. Neurons receiving glutamatergic afferents express mRNA of ionotropic glutamate receptor subunits. This study examined expression of vGluT2 and glutamate receptor subunit mRNAs in nuclei of the song pathways of male zebra finch brain by in situ hybridization. VGluT2 mRNA was revealed high density of expression in the song nuclei, namely HVC, lateral magnocellular nucleus of the anterior nidopallium, and robust nucleus of the arcopallium. Area $X$ did not show expression of vGluT2 mRNA. Nuclei in the descending motor pathway (dorsomedial nucleus of the intercollicular complex and retroambigual nucleus) were expressed vGluT2 mRNA. Target nuclei of vGluT2 mRNA-expressing nuclei showed hybridization signals for mRNAs of ionotropic glutamate receptor subunits. At least one of five subunit mRNAs (GluA1, GluA4, GluK1, GluN1, GluN2A) was expressed in song nuclei. The present findings support the existence of glutamatergic circuits in the song system in songbirds.

To cite this article: MR Karim, M Pervin and Y Atoji, 2014. Glutamatergic circuits in the song system of zebra finch brain determined by gene expression of vGluT2 and Glutamate receptors. Res. Agric., Livest. Fish. 1(1): 61-70.

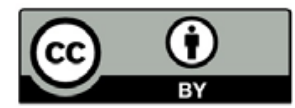

This article is an open access article licensed under the terms of the Creative Commons Attribution License.

www.agroaid-bd.org/ralf, E-mail: editor.ralf@gmail.com 


\section{INTRODUCTION}

Birdsong learning is a widely used model for studying the neural mechanisms of learning and memory. In songbirds, song production and maintenance involve networks of interconnected brain nuclei, known as the song system, which consist of two pathways (Fig. 1; Nottebohm et al., 1976; Wild, 1997; Brainard and Doupe, 2002; Zeigler and Marler, 2004; Mooney, 2009). The posterior forebrain pathway, or motor pathway, connects the HVC (letter-based proper name), the robust nucleus of the arcopallium (RA), and the tracheosyringeal motor nucleus of the hypoglossal nerve (nXIIts). The anterior forebrain pathway is a loop that projects from area $\mathrm{X}$ through a thalamic relay (medial nucleus of the dorsolateral thalamus, DLM) to the lateral magnocellular nucleus of the anterior nidopallium (LMAN) and then back to area X (Bottjer et al., 1989; Vates et al., 1997; Luo et al., 2001). The posterior and anterior forebrain pathways interact via connection through the HVC to area $\mathrm{X}$ and the LMAN to the RA(Bottjer et al., 1989; Vates et al., 1997; Zeigler and Marler, 2004). The descending motor pathway consisted of a set of nuclei including, dorsomedial nucleus of the intercollicular complex, retroambigual nucleus and tracheosyringeal motor nucleus of the hypoglossal nerve (Nottebohm et al., 1976; Wild, 1993). Pharmacological and electrophysiological studies investigating glutamatergic neurotransmission in the song system indicate that glutamate plays an important role for neuronal mechanisms of learning, memory, imprinting, or plasticity (Mooney and Konishi, 1991; Basham et al., 1999; Pinaud et al., 2008). However, glutamatergic circuits have not yet been characterized in thesong control nuclei of the songbird brain.

Glutamate is the major excitatory neurotransmitter in the mammalian brain. Vesicular glutamate transporters (vGluT1, vGluT2, vGluT3) mediate glutamate transport from the cell body to synaptic vesicles at the presynaptic terminals. Subsequently, glutamate released from the presynaptic vesicles binds to glutamate receptors on postsynaptic membranes. The mRNA for vGluT1 and vGluT2 are expressed in the majority of glutamatergic neurons in the mammalian brain, whereas vGluT3 is sparsely expressed and is found in a discrete subpopulation of non-glutamatergic neurons (Ni et al., 1994; Bellocchio et al., 1998; Fremeau et al., 2001; Herzog et al., 2001; Gras et al., 2002). In birds, vGluT2 and vGluT3 genes have been identified, but vGluT1 gene have not found. vGluT2 mRNA was widely distributed in the avian brain (Islam and Atoji, 2008; Karim et al., 2014; Atoji and Karim, 2015). VGluT2 mRNA is known to be expressed in the somata of glutamatergic neurons ( $\mathrm{Ni}$ et al., 1994; Fremeau et al., 2001; Islam and Atoji, 2008; Karim et al., 2014) and its protein is preferentially observed in the presynaptic terminals of asymmetric synapses in mammals and birds (Atoji, 2011). Thus, vGluT2 mRNA expression considers the origin of glutamatergic projections in the neural circuits. On the other hand, neurons receiving glutamatergic afferents express the mRNA of GluR subunit in the soma, which indicated the projection targets of glutamatergic neurons. Therefore, expression of vGluT2 mRNA and distributions of glutamate receptor subunit mRNAs will provide morphological cues to the glutamatergic circuits in the brain. In the present study, the origins and putative targets of glutamatergic neurons in song control nuclei or areas in the adult male zebra finch brain were examinedusing in situ hybridization assays for vGluT2 mRNA and glutamate receptor AMPA types 1 and 4 (GluA1, GluA4), kainate type 1 (GluK1), and NMDA types 1 and 2A (GluN1 and GluN2A) mRNAs.

\section{METERIALS AND METHODS}

\section{Animals}

Ten adult male zebra finches (Taeniopygia guttata, body weight: 11-22g and age: 4-7 months) were used in the present study. Animal handling procedures were approved by the Committee forAnimal Research and Welfare of Gifu University. Animals were anesthetized with sodium pentobarbital $(50 \mathrm{mg} / \mathrm{kg})$. For in situ hybridization, fresh brains were quickly removed and 
immediately frozen on powdered dry ice. Serial transverse or longitudinal sections were cut at $30 \mu \mathrm{m}$ thickness on a cryostat, thaw-mounted onto the 3-aminopropyl triethoxysilane coated slides, and stored at $-30^{\circ} \mathrm{C}$.

\section{In situ hybridization}

Slide-mounted sections were fixed in $4 \%$ paraformaldehyde in $0.1 \mathrm{M}$ phosphate buffer ( $\mathrm{pH} 7.4)$ for 15 minutes at room temperature, rinsed 3 times in $4 x$ standard saline citrate (SSC; $\mathrm{pH} 7.4 ; 1 \mathrm{x}$ SSC contains $0.15 \mathrm{M}$ sodium chloride and $0.015 \mathrm{M}$ sodium citrate), and dehydrated through a graded ethanol series $(70 \%-100 \%)$. Sections were then defatted with chloroform for 3 minutes, and immersed in $100 \%$ ethanol twice for 5 minutes. Hybridization was performed by incubating the sections at $41^{\circ} \mathrm{C}$ for overnight with the following buffer : $4 \times$ SSC, $50 \%$ deionized formamide, $0.12 \mathrm{M}$ phosphate buffer ( $\mathrm{pH} 7.4$ ), 1\% Denhardt's solution (NacalaiTesque, Kyoto, Japan), $250 \mu \mathrm{g} / \mathrm{ml}$ yeast tRNA (Roche, Mannheim, Germany), $10 \%$ dextran sulfate (NacalaiTesque), and 20 mMdithiothreitol. The buffer contained ${ }^{35} \mathrm{~S}$-dATP $(46.25 \mathrm{TBq} / \mathrm{mmol}$; PerkinElmer Life Science, Waltham, MA, USA) labeled oligonucleotide probe at the concentration of approximately 1-2 $\times 10^{7}$ $\mathrm{dpm} / \mathrm{ml}$. The probe was labeled at 3 '-end with ${ }^{35} \mathrm{~S}$-dATP by terminal deoxynucleotidyltransferase (Takara) before hybridization. After hybridization, sections were washed in $1 \mathrm{x} \mathrm{SSC}(\mathrm{pH} 7.4)$, then dehydrated through a graded ethanol series $(70 \%-100 \%)$, and exposed to X-ray films (Fuji Medical X-Ray Film, Tokyo, Japan) for 7 days. After X-ray film autoradiography, the sections were coated with NTB-2 emulsion (Eastman Kodak Company, Rochester, NY, USA) diluted 1:1 with distilled water and exposed at $4^{\circ} \mathrm{C}$ for 4 weeks in tightly sealed dark boxes. After development, the sections were fixed, washed and dehydrated. Some sections were counterstained with $0.1 \%$ cresyl violet.

\section{Oligonucleotide probes}

Antisense and sense oligo DNA probes of vGluT2 were designed based on the zebra finch vGluT2 cDNA sequence (KF964320), and synthesized commercially (Rikaken, Nagoya, Japan). Zebra finch vGluT2 anti-sense probe (vGluT2-AS) was complementary to bases 1,707-1,742 (Table 1). Sense probe (vGluT2-S) was complementary to the antisense probe. The sequence of the zebra finch vGluT2-AS probe region shows homology against vGluT2 cDNA sequence of pigeon (bases 1,699-1,734; FJ428226) with 100\%, chicken (bases 1,699-1,734; JF320001) with 94\%, rat (bases 1,699-1,737; NM_053427) and mouse (bases 1,699-1,737; NM_080853) with 69\% and human (bases 1,699-1,737; NM_020346) with 78\%, and less than 52\% homology with any other non- vGluT2 related sequences in a gene bank data base. Antisense and sense oligo DNA probes of zebra finch GluA1, GluA4, GluK1, GluN1 and GluN2A were designed based on a partial sequences of zebra finch GluA1, GluA4, GluK1, GluN1 and GluN2A cDNA sequences (Wada et al., 2004; Table 1), respectively, and were synthesized commercially (Rikaken).

\section{Image processing}

Photographs at low-power magnification were taken with a scanner (Epson GT-9300UF, Tokyo, Japan). Photomicrographs at high-power magnification were taken with a digital camera (Pro 600ES, Pixera Corporation, Los Gatos, CA, USA or Nikon, DS-Fi1, Tokyo, Japan) mounted on a light microscope. Adjustment of photographs for contrast, brightness and sharpness, layout, and lettering were performed using Adobe Photoshop 7.0J (Tokyo, Japan) and Adobe Illustrator 10.0J (Tokyo, Japan).

\section{RESULTS}

\section{Distribution of vGluT2 mRNA in the song system}

In situ hybridization, an antisense probe showed a differential expression vGluT2 mRNA in the adult male zebra finch brain, including many nuclei or areas in song system (Figs. 2A-C). A sense probe of vGluT2 mRNA did not show specific hybridization signal in X-ray film autoradiogram (Fig. 2D). 
In the song nuclei, vGluT2 mRNA expression patterns differed from the surrounding brain subdivisions (Fig. 2B, C). In all three major pallial song nuclei (HVC, RA, and LMAN) vGluT2 mRNA levels were higher than the respective surrounding brain subdivisions (Figs. 2B,C, $3 A, C, D, F)$. In addition, the HVC shelf and RA cup region showed weak expression of vGluT2 mRNA (Fig. 3C,E). Cresyl violet-stained section indicated silver grains were localized on the cell bodies of neurons in the HVC (Fig. 3D). The area X was devoid of vGluT2 mRNA similar to the surrounding striatum (Fig. 2C). Small pallial song nuclei, nuclusinterfacialis showed modrate expression of vGluT2 mRNA. In the diencephalon, vGluT2 mRNA expression was very high in the anterior portion of nucleus dorsolateralis anterior thalami, pars medialis (aDLM, Figs. 2B, 3F), which is a song nucleus part of DLM (Wada et al., 2004).

Table 1. Probes for in situ hybridization

\begin{tabular}{|c|c|}
\hline \multicolumn{2}{|l|}{ Probes } \\
\hline Anti-sense probes (zebra finch) (5'-3') & Sense probes (zebra finch) (5'-3') \\
\hline \multicolumn{2}{|l|}{ VGIUT 2} \\
\hline $\begin{array}{l}\text { TCCTTCCTTGTAGTTGTATGAGTCTTGTACTTCCTC } \\
\text { GluA1 }\end{array}$ & GAGGAAGTACAAGACTCATACAACTACAAGGAAGGA \\
\hline $\begin{array}{l}\text { GATATAGAAAACCCCCGCCACATTGCTGAGACTCAG } \\
\text { GluA4 }\end{array}$ & CTGAGTCTCAGCAATGTGGCGGGGGTTTTCTATATC \\
\hline $\begin{array}{l}\text { CTGCTAACTAGGAACAGGACCACACTGACACCAATG } \\
\text { GluK1 }\end{array}$ & CATTGGTGTCAGTGTGGTCCTGTTCCTAGTTAGCAG \\
\hline $\begin{array}{l}\text { GTCCTTGTTGCTGTCTGTCATGTTAAGGCCACTGTA } \\
\text { GluN1 }\end{array}$ & TACAGTGGCCTTAACATGACAGACAGCAACAAGGAC \\
\hline $\begin{array}{l}\text { GGGTCAGGTTCTGCTCTACCACTTTTTCTATCCTGC } \\
\text { GluN2A }\end{array}$ & GCAGGATAGAAAAAGTGGTAGAGCAGAACCTGACCC \\
\hline CCAGCTGGCTGCTCATGACTTCGTTCTTCTCGTTGT & ACAACGAGAAGAACGAAGTCATGAGCAGCCAGCTGG \\
\hline
\end{tabular}

Table 2. Hybridization intensity of glutamate receptor subunit mRNAs in major auditory and song nuclei of the zebra finch brain

\begin{tabular}{|lccccc|}
\hline Regions & GluA1 & GluA4 & GluK1 & GluN1 & GluN2A \\
\hline HVC & - & - & - & + & + \\
Lateral magnocellular nucleus of the anterior nidopallium & + & - & - & + & + \\
Nucleus robustusarcopallii & - & - & ++ & + & + \\
area X & +++ & + & - & +++ & ++ \\
Nucleus of the dorsal lateral medial thalamus & - & ++ & - & - & + \\
Nucleus interfacialis & - & - & + & - & + \\
Dorsomedial nucleus of the intercollicular complex & + & + & - & + & - \\
Nucleus retroambigualis & - & - & + & - & ++ \\
Nucleus nervihypoglossi, pars tracheosyringealis & - & - & + & - & + \\
\hline
\end{tabular}

Hybridization intensity is evaluated as follows: area X (3+, Fig. 4D, 5D), nucleus robustusarcopallii (2+, Fig. 4C, 5C) and lateral magnocellular nucleus of the anterior nidopallium (1+, Fig. 5A). 
Nuclei in the descending motor pathway was expressed vGluT2 mRNA. Particularly, vGluT2 mRNA expression was high in the dorsomedial nucleus of the intercollicular complex (DM). VGluT2 mRNA expression was moderate in the retroambigual nucleus, tracheosyringeal motor nucleus of the hypoglossal nerve (Figs. 2A, B).

\section{Distribution of ionotropic glutamate receptor subunits mRNAsin the song system}

Antisense probesfor AMPA type 1 and 4 (GluA1, GluA4), kainate type 1 (GluK1) and NMDA type 1 and 2A (GluN1 and GluN2A) mRNAs revealed differential expression of glutamate receptor subunit mRNAs in the telencephalic and midbrain vocal nuclei or areas of the zebra finch (Fig. 4AE). The sense probes did not exhibit specific hybridization signal in X-ray images and a case of GluN1 as shown as a representative (Fig. 4F).

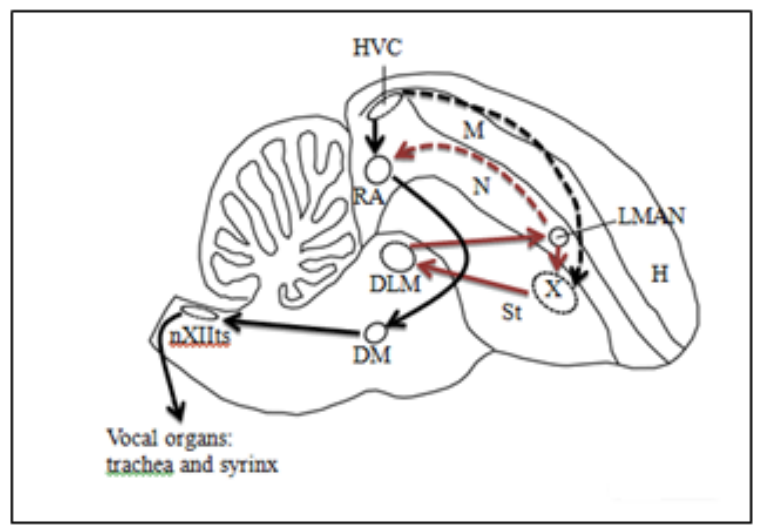

Figure 1. Schematic longitudinal section of zebra finch brain showing the song pathways with known connections. Dark black arrows represent the connections of the motor or posterior forebrain pathway (Nottebohm et al., 1976; Wild et al., 1997); red arrows (light blak for black and white print) represents the connections of the anterior forebrain pathway (Bottjer et al., 1989; Vates and Nottebohm, 1995; Vates et al., 1997; Luo et al., 2001), and dashed arrows show connection between the two pathways (Bottjer et al., 1989; Vates et al., 1997; Zeigler and Marler, 2004). DLM, nucleus of the dorsal lateral medial thalamus; DM, dorsomedial nucleus of the intercollicular complex; $H$, hyperpallium; LMAN, lateral magnocellular nucleus of the anterior nidopallium; M, mesopallium; $N$, nidopallium; RA, nucleus robustusarcopallii; HVC, letter based proper name; St, striatum; nXIlts, nucleus nervihypoglossi, pars tracheosyringealis. Scale bars $=2 \mathrm{~mm}$

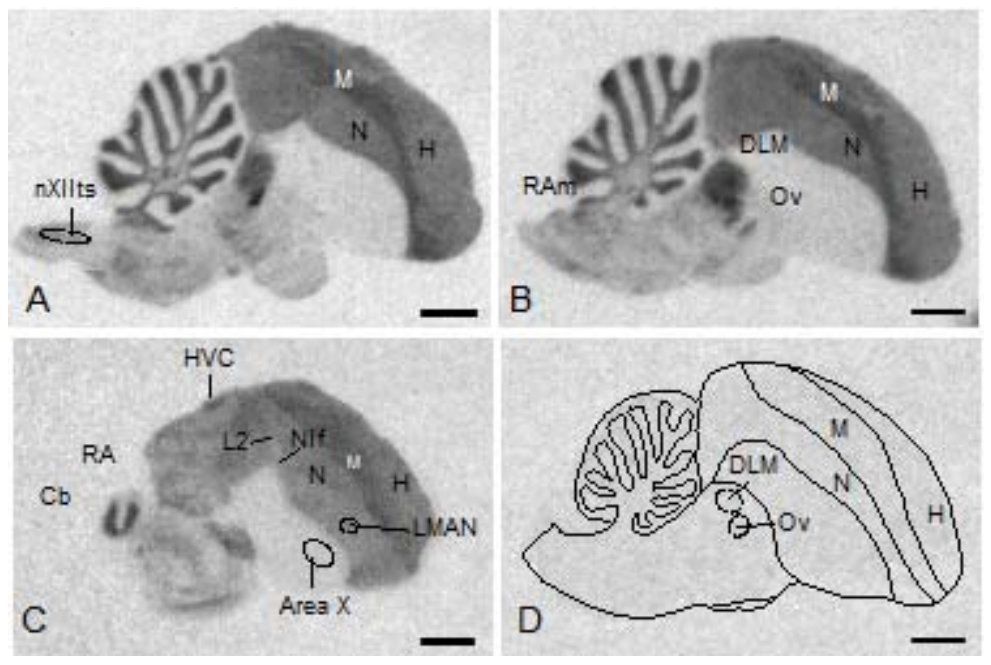

Figure 2. A-C: In situ hybridization X-ray film autoradiograms show expression of vGluT2 mRNA in medial to lateral series of longitudinal sections of the zebra finch brain. D: The sense probe shows no specific hybridization signal in the brain. A: arcopallium; H: hyperpallium; M: mesopallium; N: nidopallium, Ov: nuclus ovoidalis; St: striatum. For other abbreviations, see list. Scale bars $=2 \mathrm{~mm}$ in A-D. 


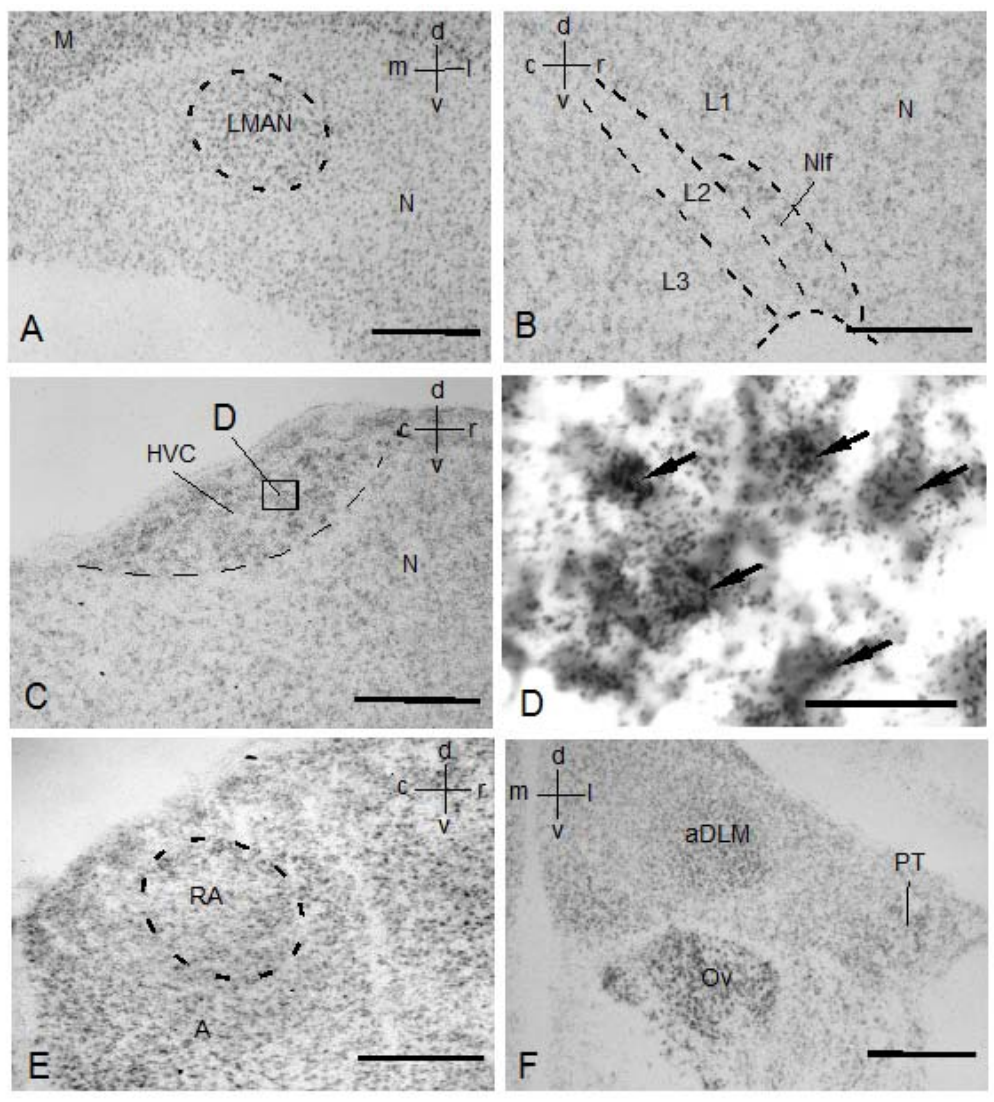

Figure 3. Photomicrographs of emulsion-coated sections show expression of vGluT2 mRNA in neurons ofsong nuclei (A, F: transverse sections, B-E: longitudinal sections). A: LMAN shows intense expression of vGluT2 mRNA than surrounding nidopallium. B: Nucleus interfacialis shows a moderate expression of vGluT2 mRNA and weak signal is seen in the field L2. C: Labeled neurons are observed in HVC. D: Enlargement of a box in $C$ after counterstaining with cresyl violet. Many silver grains are seen on the cell body neurons of HVC (arrows). E: VGluT 2 mRNA expression in RA. F: VGluT 2 mRNA expression in several thalamic nuclei. The anterior part of DLM (aDLM) and ovoidal nucleus (Ov) showed intense vGluT 2 mRNA. A: arcopallium; L1, L2, L3: field L complex; M: mesopallium; $\mathrm{N}$ : nidopallium. $\mathrm{PT}$ : pretectal nucleus. For other abbreviations, see list. Scale bars $=500 \mu \mathrm{m}$ in $\mathrm{A}, \mathrm{F} ; 150 \mu \mathrm{m}$ in $\mathrm{B}, \mathrm{C}, \mathrm{E} ; 50 \mu \mathrm{m}$ in $\mathrm{D}$.

Each of the glutamate receptor subunit mRNA expression patterns was unique and differed from the surrounding brain subdivisions including song nuclei (Figs.4A-E). Among the pallialsong nuclei, GluA1 mRNA signal was high in the area X (Fig. 4A). Area $X$ also showed weak GluA4 mRNA expression (Fig. 4B).GluK1 mRNA, subunit of kainate receptor, was expressed moderately in RA (Fig. 4C). In case of NMDA receptor subunits, GluN1 mRNA signal was high in the area $X$ (Fig. 4D, 5D). HVC and RA showed weak GluN1 mRNA expression. GluN2A mRNA signal was moderate in the area $X$ (Fig. 4E). LMAN and HVC showed weak GluN2A mRNA expression (Fig. $4 \mathrm{E}, 5 \mathrm{~A}, \mathrm{~B})$. In the diencephalic song nuclei, GluA4 mRNA expression was moderate in the anterior portion of nucleus dorsolateralis anterior thalami, pars medialis (aDLM, Fig. 5E).

Nuclei in the descending motor pathway was expressed at least one of the glutamate receptor subunit mRNA. Particularly, the dorsomedial nucleus of the intercollicular complex showed positive signal for GluA1, GluA4 and GluN1 mRNAs (Fig. 5E). The retroambigual nucleus and tracheosyringeal motor nucleus of the hypoglossal nerve showed weak or moderate signals for GluK1 and GluN2A mRNAs (Fig. 5F). Signal density of ionotropic glutamate receptor subunit mRNAs in song nuclei is shown in Table 2. 


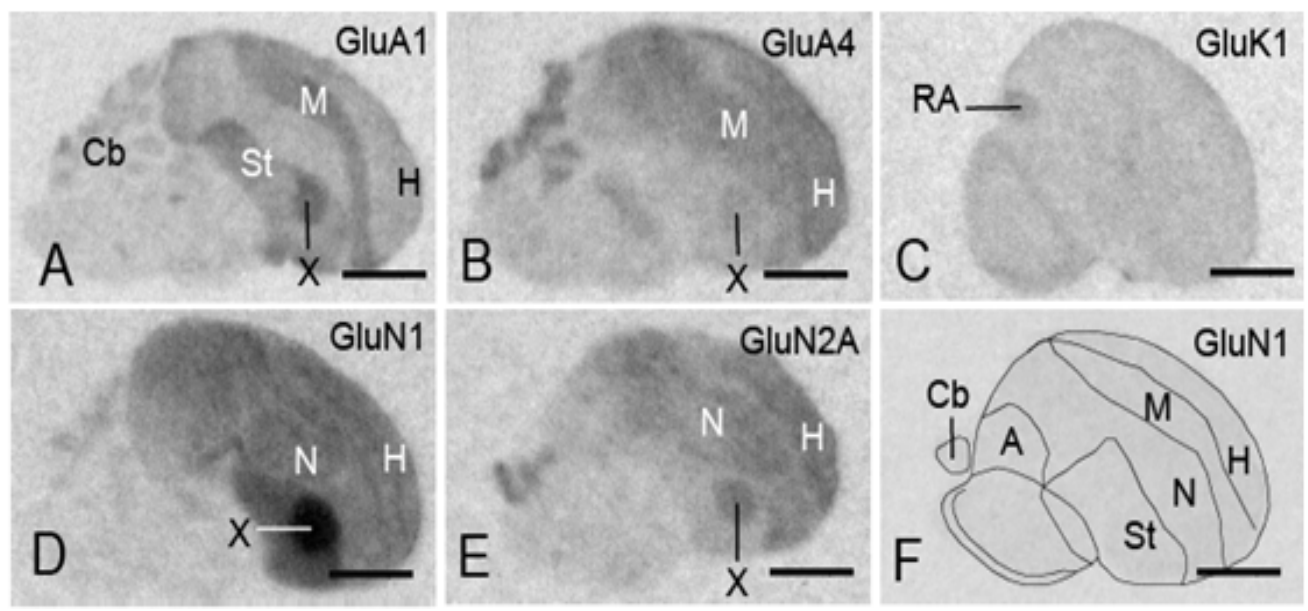

Figure 4. Ionotropic glutamate receptor subunit mRNAs in thezebra finch brain. A-H: X-ray film autoradiogramsshow differential expression of GluA1 (A), GluA4 (B), GluK1 (C), GluN1 (D) and GluN2A (E) mRNAs in longitudinal sections. F: A sense probe shows no specific hybridization signal in a X-ray film autoradiogram. A: arcopallium; H: hyperpallium; M: mesopallium; N: nidopallium, St: striatum. For other abbreviations, see list. Scale bars $=2 \mathrm{~mm}$ in A-F

\section{DISCUSSION}

Glutamatergic circuits are not well established in nuclei of the song pathway of songbird brains. Glutamatergic marker gene, vGluT2 mRNA expression in the cell body of neurons indicate the origin of glutamatergic projections. The distributions of iontropic glutamate receptor subunit mRNAs demonstrate projection portions or targets from vGlut2 mRNA-expressing neurons. Therefore, the findings in the present study indicate origins of glutamatergic neurons and their putative projection nuclei in the zebra finch brain.

\section{Glutamatergic circuits in the song system}

Glutamatergic circuits were found in the song system to the zebra finch brain. AMPA currents have been identified in these nuclei (Stark and Perkel, 1999). The HVC contains two types of excitatory neurons that project either to area $X$ or the RA as well as one type of inhibitory interneuron (Mooney, 2000; Wild et al., 2005). Projections from the HVC to the RA are sensitive to AMPA and NMDA agonists, and area $X$ is responsive to NMDA agonists (Mooney, 2000; Sizemore and Perkel, 2008). In the present study, vGluT2 mRNA-expressing glutamatergic neurons are identified in the cell bodies of neurons in the HVC. In contrast, the RA expresses glutamate receptor subunit mRNAs, including GluA2, GluK1, and GluN2A, and area X displays positive signals for GluA1, GluN1, and GluN2A mRNAs (Wada et al., 2004; present study).These results suggest that projection neurons in the HVC are glutamatergic. The RA consists of projection neurons and interneurons (Mooney and Konishi, 1991; Spiro et al., 1999; Stark and Perkel, 1999). The projection neurons send long axons to the dorsomedial nucleus of the intercollicular complex (DM), retroambigual nucleus (RAm), and racheosyringeal motor nucleus of the hypoglossal nerve (nXIIts) as well as collaterals to other projection neurons within the RA. Intense hybridization signals for vGluT2 mRNA were observed in the cell bodies of neurons in the RA whereas the DM was positive for GluA1, GluK1, and GluN2A mRNA signals (Wada et al., 2004; present study). Moreover, this study identified the expression of GluK1 and GluN2A mRNA in the RAm and nXIlts, which suggests that projection neurons in the RA are glutamatergic. It has been shown that the LMAN evokes excitatory inputs in the RA via NMDA-type receptors (Mooney, 1992; Spiro et al., 1999; Sizemore and Perkel, 2008). 

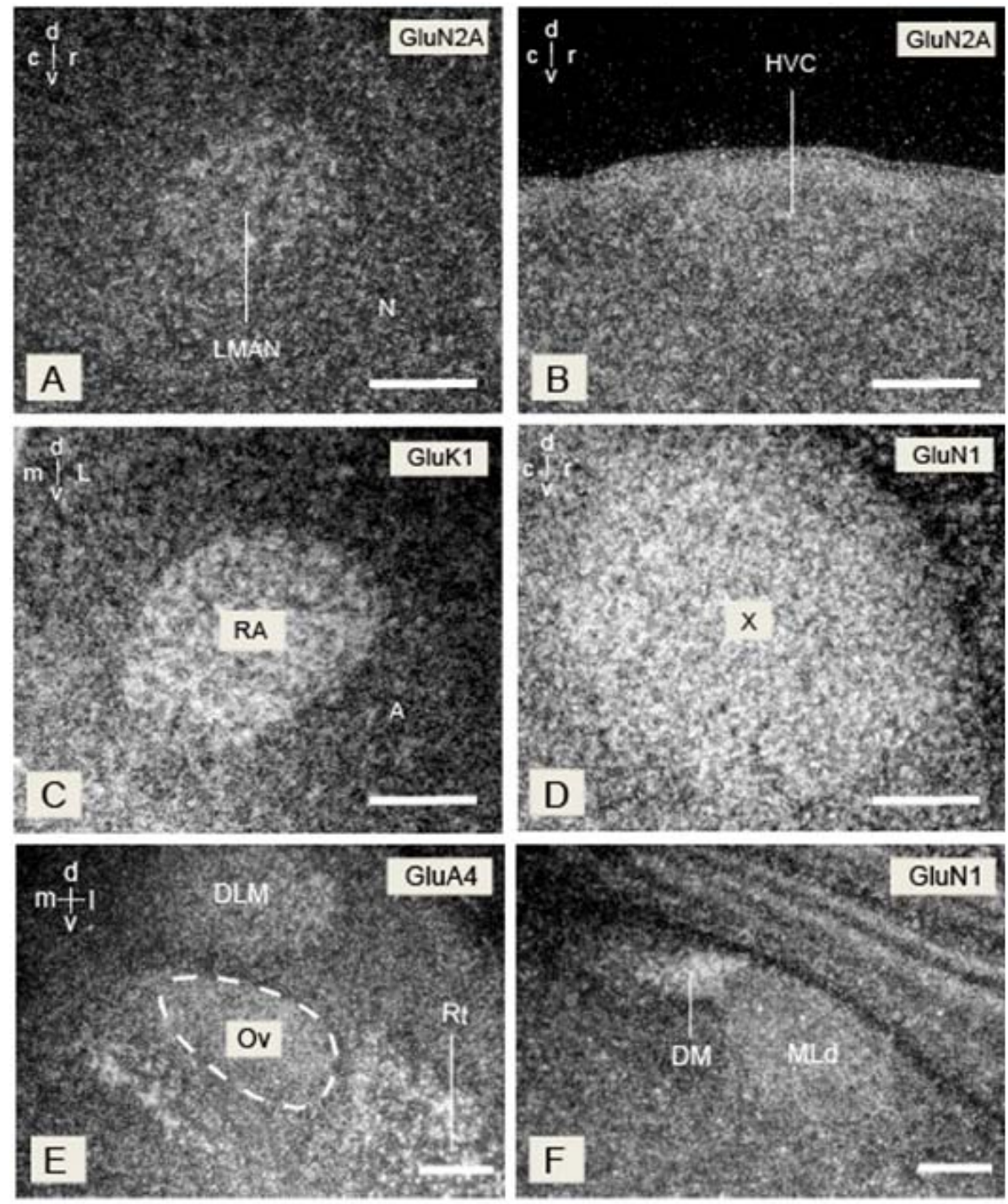

Figure 5. Photomicrograph of emulsion-coated sections show expression of glutamate receptor subunit mRNAs in various nuclei or areas of the song systemsunder dark-field illumination. GluA4 mRNA in DLM and Ov (E). GluK1 mRNA in RA (C).GluN1 mRNA in area X (D) and DM and MLd (F). GluN2A mRNA in LMAN (A) and HVC (B). A: archopallim, N: nidopallium. For other abbreviations, see list. Scale bars $=300 \mu \mathrm{m}$ A-F.

The evidence shows that the LMAN projects to area $X$ (Vates and Nottehohm, 1995) and that the RA and area $X$ are thought to be the target nuclei of glutamatergic projection neurons. The current study confirmed high distribution of vGluT2 mRNA-expressing glutamatergic neurons in the LMAN, which suggests that projection neurons in this nucleus are glutamatergic. It is known that area $\mathrm{X}$ sends projections to the DLM, and DLM projects back to the LMAN (Bottjer et al., 1989; Vates et al., 1997; Luo et al., 2001). The present study found that the DLM expresses vGluT2 mRNA as well as mRNAs for GluA1, GluA2, and GluN2D (Wada et al., 2004; present study). However, although AMPA and NMDA receptors in the DLM likely receive glutamatergic inputs from unidentified areas, this does not include area $X$ because projection neurons from area $X$ to the DLM are GABAergic (Grisham and Arnold, 1994; Luo and Perkel, 1999, 2001). Accordingly, present study did not find vGluT2 mRNA expression in area $X$. The present in situ hybridization assays for vGluT2 mRNA and ionotropic glutamate receptor subunit mRNAs support the presence of glutamatergic neurons and their target neurons or projection terminals in the HVC, RA and LMAN. 
The morphological distribution of vGluT2 and glutamate receptor subunit mRNAs song pathways support that glutamatergic circuits are involved in song production and vocal learning in songbirds.

\section{CONFLICT OF INTEREST}

Authors have declared that no conflict of interests exist.

\section{REFERENCES}

1. Atoji $Y, 2011$. Immunohistochemical localization of vesicular glutamate transporter 2 (vGluT2) in the central nervous system of the pigeon (Columba livia). Journal of Comparative Neurology, 519: 28872905.

2. Atoji $Y$ and MR Karim, 2014. Expression of vesicular glutamate transporter 3 mRNA in the brain and retina of the pigeon. Journal of Chemical Neuroanatomy, 61-62: 124-131

3. Basham ME, F Sohrabji, TD Singh, EJ Nordeen and KW Nordeen, 1999. Developmental regulation of NMDA receptor $2 \mathrm{~B}$ subunit $\mathrm{mRNA}$ and ifenprodil binding in the zebra finch anterior forebrain. Journal of Neurobiology, 39: 155-167.

4. Bellocchio EE, H Hu, A Pohorille, J Chan, VM Pickel and RH Edwards, 1998. The localization of the brain-specific inorganic phosphate transporter suggests a specific presynaptic role in glutamatergic transmission. Journal of Neuroscience, 18: 8648-8659.

5. Bottjer SW, KA Halsema, SA Brown and EA Miesner, 1989. Axonal connections of a forebrain nucleus involved with vocal learning in zebra finches. Journal of Comparative Neurology, 279: 312326.

6. Brainard MS and A Doupe, 2002. What songbirds teach us about learning? Nature 417: 351-358.

7. Fremeau RT Jr, MD Troyer,I Pahner, GO Nygaard, CH Tran, RJ Reimer, EE Bellocchio, D Fortin, J Storm-Mathisen and RH Edwards, 2001. The expression of vesicular glutamate transporters defines two classes of excitatory synapse. Neuron, 31: 247-260.

8. Gras C, E Herzog, GC Bellenchi, V Bernard, P Ravassard, M Pohl, B Gasnier, B Giros and S EI Mestikawy, 2002. A third vesicular glutamate transporter expressed by cholinergic and serotoninergic neurons. Journal Neuroscience, 22:5442-5451.

9. Grisham W and AP Arnold. 1994. Distribution of GABA-like immunoreactivity in the song system of the zebra finch. Brain Research, 651: 115-122.

10. Herzog E, GC Bellenchi, C Gras, V Bernard, P Ravassard, C Bedet, B Gasnier, B Giros and S El Mestikawy, 2001. The existence of a second vesicular glutamate transporter specifies subpopulations of glutamatergic neurons. Journal of Neuroscience, 21:RC181 (1-6).

11. Islam MR, and $Y$ Atoji, 2008. Distribution of vesicular glutamate transporter 2 and glutamate receptor 1 mRNA in the central nervous system of the pigeon (Columba livia). Journal of Comparative Neurology, 511: 658-677.

12. Karim, MR, S Saito and $Y$ Atoji, 2014. Distribution of vesicular glutamate transporter 2 in auditory and song control brain regions in the adult zebra finch (Taeniopygia guttata). Journal of Comparative Neurology, 522, 2129-2151.

13. Luo M, and DJ Perkel, 1999. A GABAergic strongly inhibitory projection to a thalamic nucleus in the zebra finch song system. Journal of Neuroscience, 19: 6700-6711.

14. Luo M, Ding L and DJ Perkel, 2001. An avian basal ganglia pathway essential for vocal learning forms a closed topographic loop. Journal of Neuroscience, 21:6836-6845.

15. Mooney R, 2000. Different subthresholdmechanism underlie song selectivity in identified HVc neurons of the zebra finch Journal of Neuroscience, 20: 5420-5436.

16. Mooney R, 2009. Neural mechanisms for learned birdsong. Learn Mem 16: 655-669.

17. Mooney R, and M Konishi, 1991. Two distinct inputs to an avian song nucleus activate different glutamate receptor subtypes on individual neurons. Proceedings of the National Academy of Sciences of the United States of America, 88: 4075-4079. 
18. Ni B, Rosteck PR Jr, NS Nadi and SM Paul, 1994. Cloning and expression of a cDNA encoding a brain-specific $\mathrm{Na}^{+}$-dependent inorganic phosphate cotransporter. Proceedings of the National Academy of Sciences of the United States of America, 91: 5607-5611.

19. Nottebohm F, TM Stokes and CM Leonard, 1976. Central control of song in the canary, Serinuscanarius. Journal of Comparative Neurology, 165: 457-486.

20. Pinaud R, TA Terleph, LA Trere, ML Phan, AA Dagostin, RM Leão, CV Mello and DS Vicario, 2008. Inhibitory network interactions shape the auditory processing of natural communication signals in the songbird auditory forebrain. Journal of Neurophysiology, 100: 441-455.

21. Sizemore $M$ and DJ Perkel, 2008. Noradrenergic and $G A B A_{B}$ receptor activation differentially modulate inputs to the premotor nucleus RA in zebra finches. Journal of Neurophysology, 100:8-18.

22. Spiro JE, MB Dalva and R Mooney. 1999. Long-range inhibition within zebra finch song nucleus RA can coordinate the firing of multiple projection neurons. Journal Neurophyisology, 81:3007-3020.

23. Stark LL and DJ Perkel, 1999. Two-stage, input-specific synaptic maturation in a nucleus essential for vocal production in the zebra finch. Journal of Neuroscience, 19: 9107-9116.

24. Vates GE and F Nottebohm, 1995. Feedback circuitry within a song-learning pathway. Proceedings of the National Academy of Sciences of the United States of America, 92: 5139-5143.

25. Vates GE, Vicario DS and F Nottebohm, 1997. Reafferentthalamo-'cortical' loops in the song system of oscine songbirds. Journal of Comparative Neurology, 380: 275-290

26. Wada K, H Sakaguchi, ED Jarvis, and M Hagiwara, 2004. Differential expression of glutamate receptors in avian neural pathways for learned vocalization. Journal of Comparative Neurology, 476:44-64.

27. Wild JM, 1993. Descending projections of the songbird nucleus robustusachistriatalis. Journal of Comparative Neurology, 338: 225-241.

28. Wild JM, 1997. Neural pathways for the control of birdsong production. Journal of Comparative Neurology, 33: 653-670.

29. Wild JM, D Li, and C Eagleton, 1997. Projections of the dorsomedial nucleus of the intercollicular complex (DM) in relation to respiratory-vocal nuclei in the brainstem of pigeon (Columba livia) and zebra finch (Taenopygiaguttata). Journal of Comparative Neurology, 377: 392-413.

30. Wild JM, MN Williams, GJ Howie and R Mooney, 2005. Calcium-binding proteins define interneurons in HVC of the zebra finch (Taeniopygiaguttata). Journal of Comparative Neurology, 483: 76-90.

31. Zeigler HP and P Marler, 2004. Behavioral neurobiology of birdsong: New York Academy of Sciences, 1016: 755-758. 